\title{
Current perspectives in percutaneous atrial septal defect closure devices
}

This article was published in the following Dove Press journal:

Medical Devices: Evidence and Research

15 July 2015

Number of times this article has been viewed

\section{$\mathrm{N}$ Bissessor ${ }^{1-4}$}

'Department of Cardiology, The Epworth Hospital, Melbourne, VIC, Australia; ${ }^{2}$ Division of Interventional Cardiology, The Alfred Hospital, Melbourne, VIC, Australia;

${ }^{3}$ Department of Clinical Science, Charles Sturt University Albury Campus, NSW, Australia; ${ }^{4}$ Heart Foundation, Griffith University, QLD, Australia

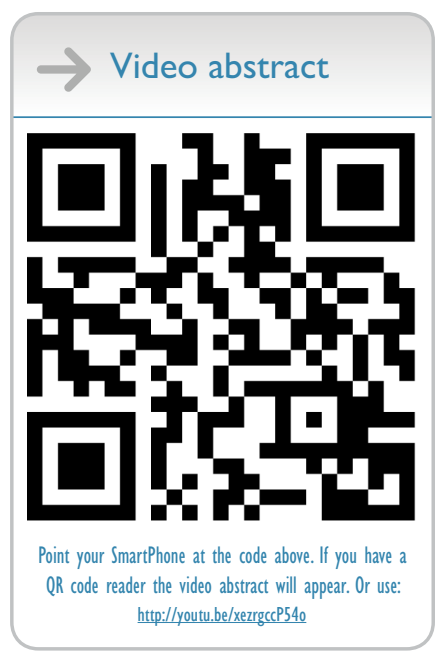

Correspondence: $\mathrm{N}$ Bissessor Department of Cardiology, The Epworth Hospital, 89 Bridge Rd, Richmond VIC $3|2|$, Australia

Tel +6I 394266666

Fax +6I 260215001

Email naylinbissessor@hotmail.com
Abstract: In the last decade, percutaneous atrial septal defect (ASD) closure has become the treatment of choice in most clinical presentations of ASD. Percutaneous ASD closure has established procedural safety through operator experience and improved device structure and deliverability. There have also been advances in diagnostic capabilities. Devices have evolved from large bulky meshes to repositionable, minimal residual mesh content that easily endothelializes and conforms well to surrounding structures. Biodegradable technology has been introduced and will be closely watched as a future option. The evolution of ASD closure device usage in the last four decades incorporates development that minimizes a wide range of serious side effects that have been reported over the years. Complications reported in the literature include thrombus formation, air embolization, device embolization, erosions, residual shunts, and nickel hypersensitivity. Modern devices have intermediate to long term data with outcomes that have been favorable. Devices are available in multiple sizes with improved delivery mechanisms to recapture, reposition, and safely close simple and complex ASDs amenable to percutaneous closure. In this review, commonly used devices and deployment procedures are discussed together with a look at devices that show promise for the future.

Keywords: ASD, congenital, Amplatzer, Gore Helex, Biostar, Figulla

\section{Background}

Atrial septal defect (ASD) is defined as a persistent communication between the right and left atria. ASD is one of the most common adult congenital defects comprising $7 \%-10 \%$ of all congenital heart defects in adults. ${ }^{1}$ Percutaneous transcatheter closure of ASD has become the preferred management strategy instead of open heart surgery. ${ }^{2}$ In 1976, King and Mills performed the first successful percutaneous ASD closure. The procedure has been improved with user-friendly delivery systems and devices. The use of new percutaneous closure devices is associated with a low rate of complications and good long-term outcomes. ${ }^{2}$ The risk of device embolization, thrombus formation, bleeding, erosion, and residual leak has decreased due to operator experience and improved quality of product. Each device has its own technical difficulty and sizing requirements to overcome the deployment learning curve. Commonly used US Food and Drug Administration (FDA) approved ASD closure devices are the Amplatzer (St Jude Medical, Inc., Saint Paul, MN, USA) and the Gore Helex (WL Gore \& Associates, Inc., Newark, DE, USA) closure devices. Operators trained in the percutaneous treatment of structural heart disease are able to navigate through the inferior vena cava and right atrium using a range of devices and delivery sheaths. The aim is to deploy an appropriately sized device in the defect to prevent any significant shunt 
between the two chambers using a combination of angiographic and echocardiographic guidance techniques.

\section{Anatomical types of ASD}

The ostium secundum defect is the most common ASD, accounting for $70 \%$ of all ASDs. It is due to an abnormal development of the septum that separates the left and right atrial chambers. ${ }^{1}$ This results in a persistent communication at the level of the fossa ovalis. ${ }^{1}$ There are other types of ASD. The primum ASD, positioned inferiorly near the crux of the heart; the sinus venosus ASD, located superiorly near the superior vena cava entry or inferiorly near the inferior vena cava entry; and the uncommon coronary sinus septal defect, which causes shunting through the ostium of the coronary sinus. ${ }^{1-4}$ Only the central defect of the septum secundum type is amenable to percutaneous closure. ${ }^{1}$

\section{Pathological effect of ASD}

ASD results in volume overload of the pulmonary circulation and right ventricle through left to right shunting between the atria. This can be detected clinically by auscultating a murmur along the left sternal border, but $5 \%$ of ASDs do not produce a murmur. The diagnosis is confirmed by right heart catheterization or echocardiography with color flow Doppler that can be diagnostic even in subclinical shunts. ${ }^{1,2}$ In advanced disease, severe increases in right-sided pressures may cause shunt reversal, which portends a poor prognosis., ${ }^{2,3}$ The consequent right to left shunt causes deoxygenated blood to enter the systemic circulation triggering cyanosis. Closure of the ASD is recommended well before shunt reversal occurs at the first sign of right atrial or right ventricular enlargement. ${ }^{1,4}$ If left untreated, ASD can produce atrial arrhythmias and right sided heart failure. Hence early detection of the defect is imperative for an optimal outcome.

\section{Indications for ASD closure}

The indications for ASD closure are pulmonary hypertension, right ventricle (RV) dysfunction (volume overload), atrial arrhythmias, exertional dyspnea and decreasing exercise capacity, shunt ratio >1.5:1 (Qp:Qs) or paradoxical embolism., ${ }^{1,4}$

\section{Defect size classification}

Defects are classified into simple defects 4-26 mm in diameter or complex defects $>26 \mathrm{~mm}$ in diameter including defects with a rim deficiency. 4,5

\section{Diagnosis}

In the modern era the diagnosis is usually made by transthoracic echocardiogram (TTE) and transesophageal echocardiography (TEE). ${ }^{4,5}$ The TEE assesses the following: shunt presence, direction, shunt ratio, defect size, position, presence of pulmonary hypertension, and right ventricular dysfunction. ${ }^{4,5}$ The defect complexity is determined by the ASD rim size, defect diameter, shunt ratio, shunt direction, interatrial septal aneurysm excursion, floppy adjacent tissue and proximity to aorta. ${ }^{4}$ Rim deficiency is an important indicator of potential complications especially with values less than $5 \mathrm{~mm}$ in anterior, inferior or superior aspects of the ASD. ${ }^{1,4,5}$ Case selection for percutaneous closure will be determined by the echo imaging characteristics of the ASD and facilitates the choice of brand of device that will be used.

\section{Deployment procedure}

A combination of TEE or intracardiac echocardiography and fluoroscopy is used to deliver, position, and deploy the closure device. The patient is required to have optimal hydration with intravenous fluid and is kept nil by mouth if general anesthesia is used. Venous access from the right femoral vein is obtained. Using a $6 \mathrm{~F}$ sheath, an Amplatz stiff wire crosses the defect and is placed in the superior pulmonary vein. The size of the sheath is determined by the size of the device. The common procedural risks include air embolization and technical difficulties in crossing the defect, which may be due to cardiac rotation or chamber remodeling. Multimodality imaging provides ancillary information to confirm crossing of the defect and balloon positioning for sizing. ${ }^{6}$

Balloon sizing using TEE and fluoroscopy can assess the defect size to obtain an appropriate waist diameter of the closure device. The waist size determines the left atrial disk dimension, which can approximate the aorta and create a potential risk for erosion. ${ }^{1,7}$

The ASD balloon-sizing diameter classifies the defect into simple or complex defects. Simple defects are less than $26 \mathrm{~mm}$ with an adequate landing zone on the rim greater than $5 \mathrm{~mm}$. Closable complex defects are greater than $26 \mathrm{~mm}$ but less than $38 \mathrm{~mm}$ in diameter. Large defects may have a deficient rim $(<5 \mathrm{~mm})$, double defects or fenestrated defects. Defects $>38 \mathrm{~mm}$ on TTE are usually referred to surgery. ${ }^{1,4}$

Contraindications to transcatheter device closure include small shunt size Qp:Qs $<1.5: 1$ or high pulmonary vascular resistance $>8$ woods units on $100 \%$ oxygen during cardiac catheterization using the Fick principle and oximetry. ${ }^{1,7}$

\section{Sizing of ASD}

The stretched balloon diameter is a useful technique to optimize defect sizing, which determines the size of the device to be deployed. ${ }^{4,7}$ The ASD closure procedure requires the use of general anesthesia since TEE is performed in most instances. 
However, a number of centers use intracardiac echocardiography imaging or even TTE (especially in smaller ASDs) to avoid the discomfort and expense of general anesthesia. Preoperative aspirin is given 12 hours before and antibiotics 1 hour before the procedure. During the procedure, the patient is anticoagulated with heparin $70 \mathrm{u} / \mathrm{kg}$ to obtain an activated clotting time $>250$.

The sizing balloon is tracked over the Amplatz stiff wire to the defect site. The balloon is expanded with a dilute contrast solution until color flow Doppler on TEE disappears. The stretched balloon diameter is measured when the defect is completely occluded. The stretched diameter determines the connector waist size, which is usually chosen at 1-2 mm over the stretched diameter size. Oversizing the device to achieve stability if the septum is flimsy is not necessary and may result in erosion of the device. The device is then deployed and tested by pushing and pulling on the cable to confirm stability prior to release of the device.,

\section{Successful closure}

Successful closure implies complete closure with residual shunt $<1-2 \mathrm{~mm}$ and stable device position. The Boutin classification for residual shunt is as follows: mild $<1-2 \mathrm{~mm}$; moderate $2-4 \mathrm{~mm}$ and large $\geq 4 \mathrm{~mm} .{ }^{8}$ Mild-moderate shunts may improve or disappear with endothelialization of the device. Long-term success is associated with a decrease in RV size, decrease in pulmonary hypertension, inhibition of any shunt and absence of an arrhythmia.

\section{Complications}

Bleeding can occur due to the use of aspirin, heparin, and post procedure clopidogrel. This may include gastrointestinal or intracranial bleeding that may require a transfusion. Other complications include prolonged procedural time; suboptimal deployment position with moderate to severe residual shunts, device embolization, atrial arrhythmias, catheter-related thrombus formation, air embolism, pericardial effusion, transient ischemic attack or stroke. , $^{7}$

Post ASD closure atrial arrhythmias can occur in 2\%-4\% of cases. The arrhythmias are due to the foreign body inflammatory response and usually resolve with medical therapy. atrio-ventricular conduction block and on occasion complete heart block may be seen and have been treated with dexamethasone therapy, but may require a permanent pacemaker in some cases.

Day 1 post procedure, a chest X-ray and TTE may be obtained to exclude device embolization $(0.1 \%)$, pericardial effusion $(0.5 \%)$, device thrombus, residual shunt, progressive valvular regurgitation, or aortic wall erosion.
Follow-up is usually done at day 1 , then 6 or 12 months. Clopidogrel is recommended for 1 month and aspirin for 6 months unless other indications exist to continue dual antiplatelet therapy. ${ }^{6}$ ASD closure can also be performed on an outpatient basis, especially if general anesthesia is not used.

\section{Devices}

\section{Amplatzer septal occluder (ASO)}

The ASO device is FDA approved since 2001 for closure of ASD and has the widest usage (Figure 1). ${ }^{1,9}$ The ASO is easily visualized on TEE and fluoroscopy. Based on ease of delivery, support and proctoring, ASO has the most outcome data for all ASD closure devices over the last 20 years. Its straightforward deployment and proven efficacy in both simple and complex lesions has made it most popular for ASD closure. ASO may also be used for off label patent foramen ovale closure. The device enjoys a high success rate due to ease of deployment and is repositionable before final deployment. The deployed device conforms to the shape of surrounding structures. The device structure is a self-expanding double disk with larger left atrial disk and a starting size $4 \mathrm{~mm}$ connector waist. The structure is a nitinol metal wire mesh framework and is recapturable. There are 26 disk sizes measured at the waist from $4 \mathrm{~mm}$ to $38 \mathrm{~mm}$. The ASO right disk/ left disk size combinations include $18 / 18 \mathrm{~mm}, 25 / 18 \mathrm{~mm}$, $30 / 30 \mathrm{~mm}, 35 / 25 \mathrm{~mm}$ combinations. The delivery sheath sizes range from $6 \mathrm{~F}$ to $12 \mathrm{~F}$. In cases with large ASDs where positioning the ASO device may be difficult, a Hausdorf sheath may facilitate deployment. The most serious risk would be device erosion, which is associated with oversizing the device or rim deficiency. It is unclear what the actual device erosion rate is; there are 240 cases reported with an estimated

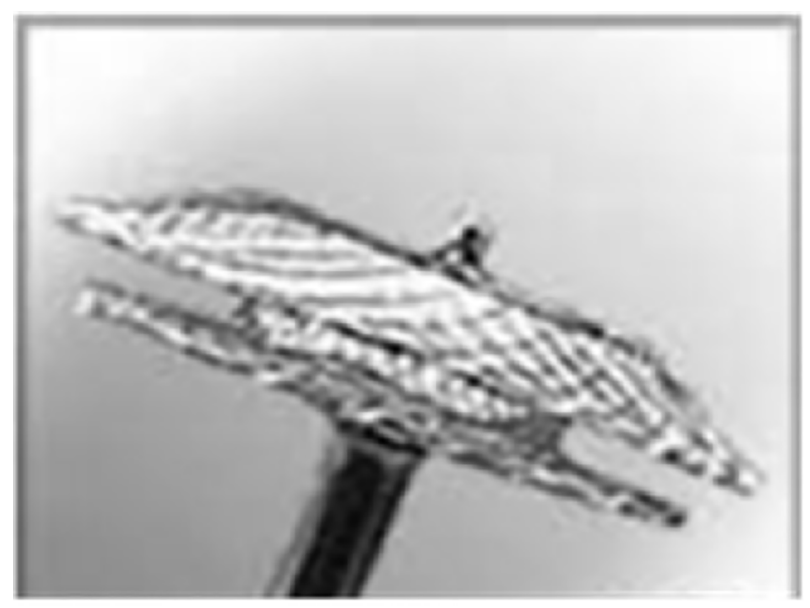

Figure I Amplatzer septal occluder - St Jude Medical, Inc., Saint Paul, MN, USA (most widely used). 
worldwide implant rate of 240,000 devices $(0.1 \%)$ but is also estimated at $0.2 \%-0.5 \%{ }^{9,10}$ The mechanism is thought to be due to friction between the left atrial disk wire mesh and the aortic or atrial wall. TTE may detect the aorto-atrial fistula or pericardial effusion but the event is so rare that it is not clear if routine TTE surveillance is worthwhile. Surgical removal of the device and patch closure of the defect is reported. The FDA has required the manufacturer to undertake a prospective study to better understand the ASO performance and the potential to develop erosions. ${ }^{2}$

\section{Gore Helex septal occluder}

The FDA approved this device for ASD closure in $2006 .^{11}$ The device consists of a corkscrew type nitinol wire frame covered by a protective Gore-Tex (expanded polytetrafluoroethylene) coating. The success rate for deployment is high with major adverse events of 3.6\% (12). No reported cases of erosions have been described for the Gore Helex device, consistent with the softer material of PTFE compared with a metal mesh. The Gore Helex device has an interesting engineering design and is retrievable but it requires a moderate learning curve to deploy the disks and understand the subtleties of its construction (Figure 2).

\section{Gore septal occluder (GSO)}

The Gore Helex device has been upgraded to the GSO (WL Gore \& Associates, Inc.) with a flexible petal design, platinum core instead of solid nitinol, delivery handle and a porous coating (Figure 3). ${ }^{11,12}$ These factors play an important role

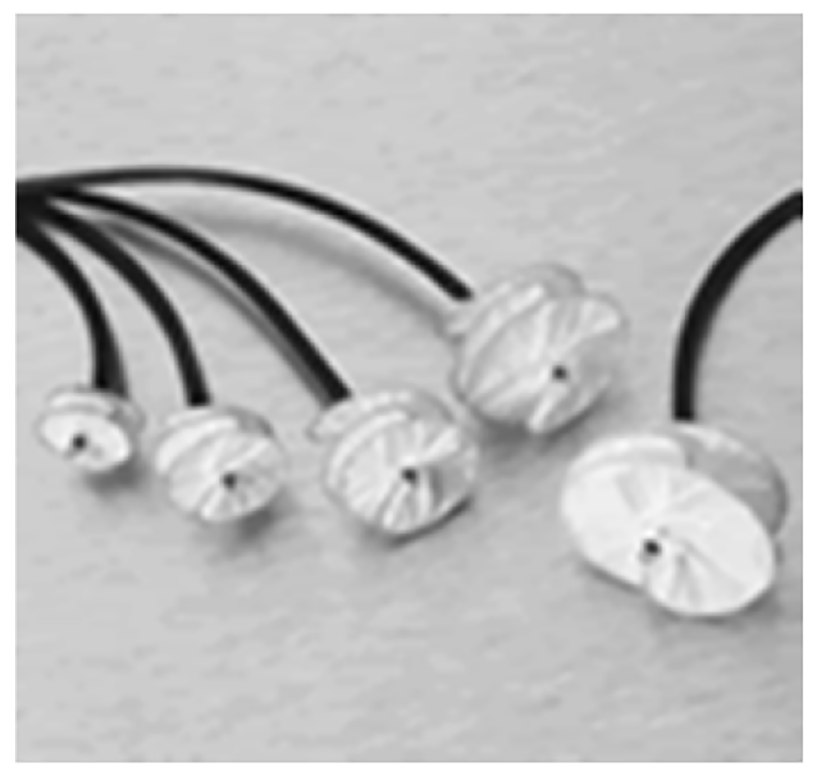

Figure 2 Gore Helex septal occluder (WL Gore \& Associates, Inc., Newark, DE, USA).

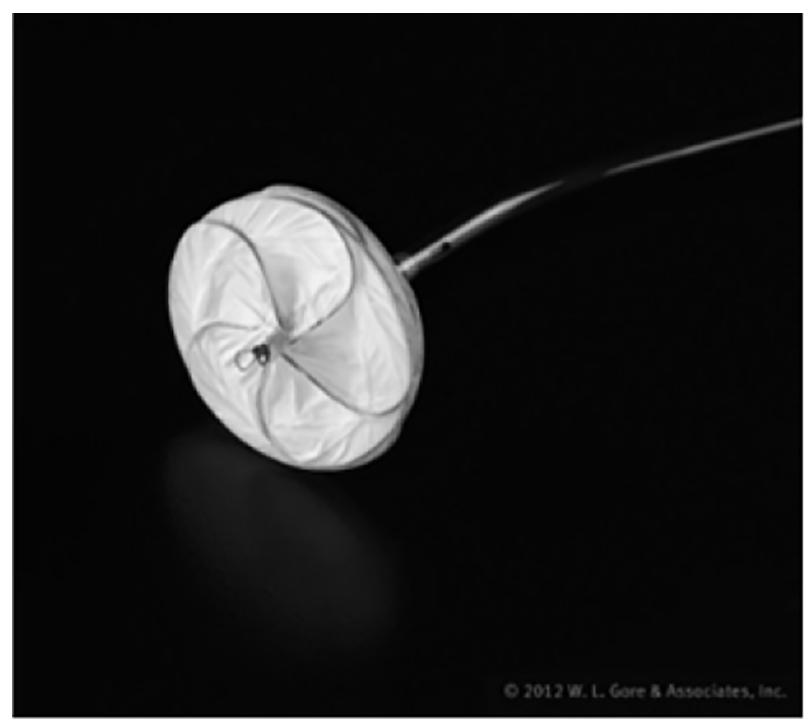

Figure 3 Gore septal occluder (WL Gore \& Associates, Inc., Newark, DE, USA).

in delivery and conformation to the surrounding structures. Excellent deployment success (89\%) with an acceptable small residual shunt is reported with GSO. ${ }^{11,12}$ The GSO proponents claim a benefit of GSO over ASO in deficient rim complex ASDs. Deficient rim is considered a contraindication to ASO in some centers due to the increased rate of erosions in this setting. ${ }^{11}$ The GSO has a softer disk with less frictional forces, which is a safety feature against erosion. Initial studies suggest that the GSO has potential benefits from a safety, efficacy, repositionable, and recapturing point of view. Residual shunts were comparable to existing devices with a proven track record. ${ }^{11}$

\section{Cera septal occluder}

Cera is new, less expensive double disk ASD occluder (Lifetech Scientific Corporation, Shenzen, People's Republic of China) (Figure 4). Cera is not FDA approved. The structure includes a self-expandable nitinol frame covered with bioceramic titanium nitride (TiN) coating. The left disk is larger than the right disk with a short $4 \mathrm{~mm}$ connecting waist. ${ }^{13}$

A recently published study compared 405 patients who were non-randomized to Cera $(n=205)$ or the ASO $(n=200)$ for simple and complex ASD closure with a mean follow-up of 13 months. ${ }^{13}$ The prospective study conducted from 2004 to 2012 attempted to adopt standardized credible assessment and procedural principles. Non-inferiority safety and feasibility of the Cera device was demonstrated with a high success in deployment rate (97\%) and $<2 \mathrm{~mm}$ residual shunt in both groups $99.5 \%$ at end of follow-up. The sustained efficacy of ASO was maintained in keeping with its established track 


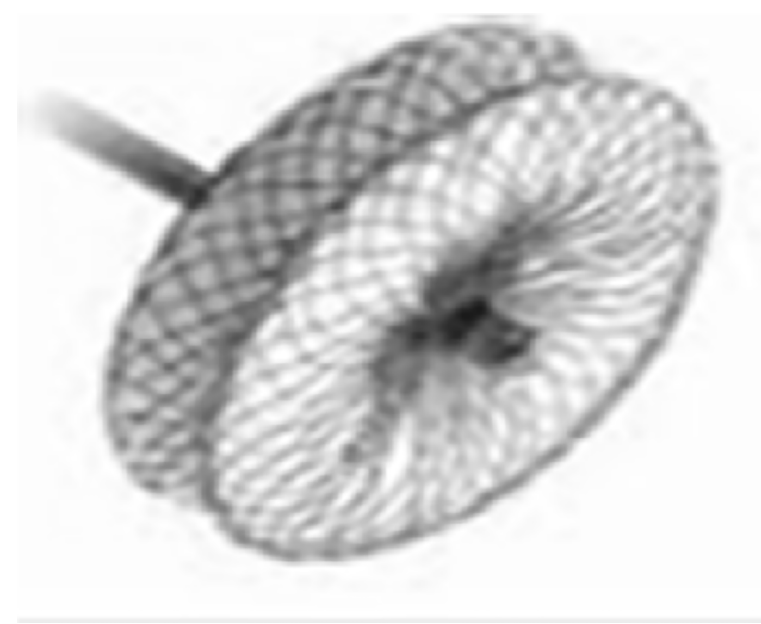

Figure 4 Cera septal occluder (Lifetech Scientific Corporation, Shenzen, People's Republic of China).

record. Despite the presence of complex lesions in $25 \%$ of cases, device embolization was only $1 \%$. Embolization was largely due to device under-sizing despite experienced operators; all devices were retrieved. ${ }^{13}$

The TiN coating on the Cera claims to be associated with less thrombosis, less nickel ion elution and facilitates endothelial tissue growth. ${ }^{13}$ The inner nitinol frame contains two disks and the central waist connector is covered by an expandable polytetrafluorethylene membrane. There are 19 sizes from $6 \mathrm{~mm}$ to $42 \mathrm{~mm}$ determined by the connector waist. Sheath sizes range from $7 \mathrm{~F}$ to $14 \mathrm{~F}$ depending on device choice. The device is deemed safe and feasible for secundum type defects with a similar deployment technique as with the ASO device, hence a small learning curve.

Large defects require a large sheath 14F, which might be a shortcoming of the device. This includes vascular complications and air embolism. Advantages over ASO include a significant cost saving of the device since it is made in People's Republic of China, up to US $\$ 2,100$. There may be better biocompatibility with the TiN coating, which allows slow release of nitinol especially in nickel hypersensitive patients, earlier endothelialization, and a reduction in thrombotic risk. However, this is also true for the Gore Helex device. No documented thrombus formation was seen but the number of cases is still small. No cerebrovascular event was seen. ${ }^{13}$ Nickel allergy with current ASD devices remains a significant side effect with device extractions reported in the literature. ${ }^{14}$

Cera devices up to $42 \mathrm{~mm}$ (maximum $38 \mathrm{~mm}$ in ASO) create percutaneous options for large defects. The device was used in large defects with deficient rims with good success at a 1-year average follow-up. ${ }^{13}$
Short procedural times and the ASO technical learning curve make the transition easier to the Cera device. However long-term safety data beyond 18 months are not available. So despite initial promising results with attractive cost savings, caution should be observed when using devices with limited long-term data and attractive cost savings. A randomized controlled trial would provide further insight into this comparative assessment.

\section{Clamshell, CardioSEAL, and Starflex}

In the last 25 years the original Clamshell device was upgraded to the CardioSEAL, which was then further upgraded to the Starflex (NMT Medical, Boston, MA, USA) (Figure 5). Device fractures were highest with the Clamshell, which was made of stainless steel, and Dacron. The CardioSEAL was made of a different metal alloy and less prone to fractures. The Starflex provided a framework from which the least amount of fractures was seen based on the flexibility of the metal hinge points. Starflex also offered improved positioning and deliverability. These device are no longer manufactured due to evolution in the industry in deliverability, device bulkiness, and complication risk. The CardioSEAL and Starflex device played a crucial role in establishing early safety, efficacy, and success in percutaneous ASD closure versus surgical closure..$^{15}$ Use of these devices has been associated with a higher risk of left atrial thrombus, which can result in stroke, and was detected on TEE at 1 month in $7 \%-23 \%$ of implants. ${ }^{15}$

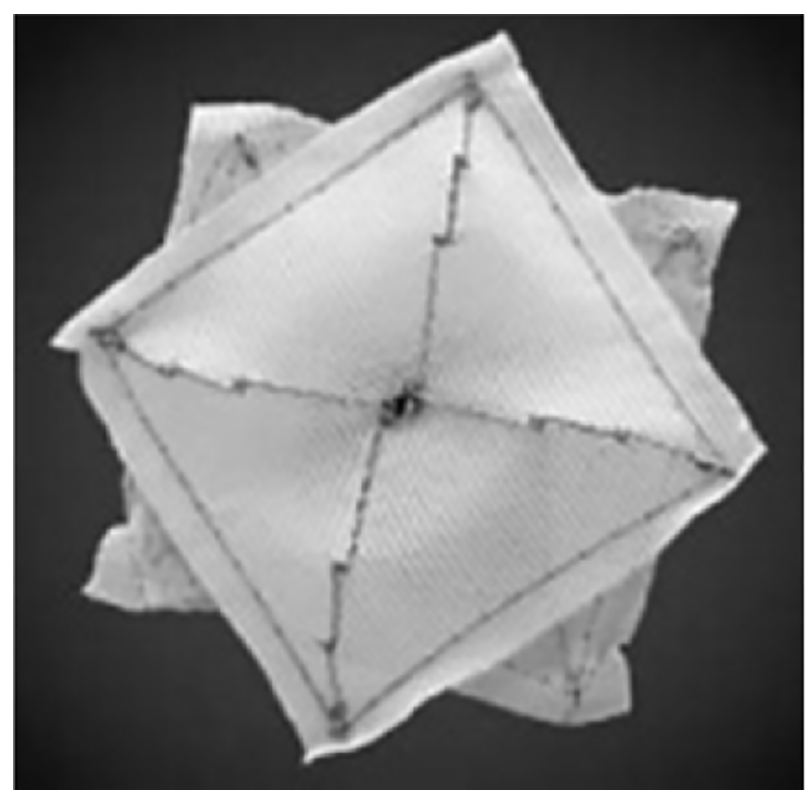

Figure 5 Starflex CardioSEAL (NMT Medical, Boston, MA, USA). 


\section{Biostar}

Biodegradable technology has the potential of revolutionizing percutaneous interventional procedures. The Biostar (BIOSTAR, NMT Medical, Boston, MA, USA), a biodegradable ASD closure device was tested on 33 children. ${ }^{16,17}$ Biostar has the structure of the Starflex without the polyester disk (Figure 6). ${ }^{17}$ The Biostar has a porcine collagen matrix on a cobalt based alloy framework. The bioengineered collagen constitutes $90 \%$ of the structure and degrades, leaving healthy native tissue on the $10 \%$ residual framework. Mid-term outcomes at 7 months have shown safety and efficacy with a deployment success rate reported at $97 \%$ and comparable residual shunt rates. ${ }^{16,17}$

It would be attractive to deploy a device that successfully closes a shunt and leaves minimal residual content through biodegradable coatings. The objective is to restore the treated area with tissue that is predominantly produced by the host surrounding tissue in response to an initial platform created by a biodegradable device structure. Soft tissue regrowth and endothelialization over the device using biodegradable material may permanently close the defect with minimal long-term squeal. Whether the integrity of the seal remains intact over a long-term period is still unknown. There are other bioabsorbable ASD devices (Biotrek) being investigated that hope to restore the atrial septum with natural tissue with no residual foreign content. ${ }^{17}$

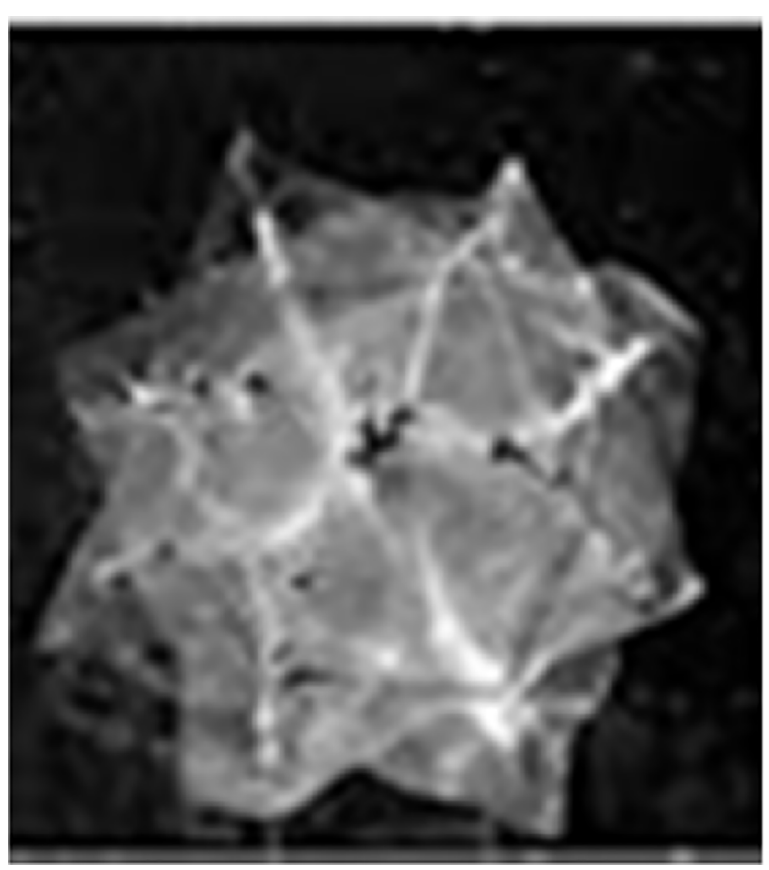

Figure 6 Biostar (biodegradable) septal occluder.

\section{Figulla Flexible Occlutech septal occluder (FSO)}

The FSO is a flexible nitinol mesh that constitutes the left and right disks (Occlutech GmbH, Jena, Germany) (Figure 7). ${ }^{18,19}$ The device is very similar to the ASO with the absence of the connecting microscrew, which improves flexibility. There have been multiple lawsuits between the companies for patent infringement. The nitinol mesh disks are filled with polyester patch with the left ball shaped disk smaller than the right disk. This difference may improve right-sided septal alignment and a smaller, flexible left sided profile. ${ }^{18,19}$ The ball and socket delivery mechanism allows for greater flexibility during deployment, which may be beneficial for large ASDs and deficient rims despite inexperienced operators. Angles are created between the left and right disks which conform to superior alignment after release. ${ }^{18}$ These unique features make it an attractive option for complex defects where erosions with ASO have occurred.

In a retrospective comparison, $31 \mathrm{FSO}$ deployments in ASD were compared to 131 ASO device occlusions. FSO demonstrated a $93 \%$ success rate in deployment with comparable safety and efficacy. ${ }^{18}$ However, preliminary data with the Figulla device are limited compared to the enormous experience with the Amplatzer devices. ${ }^{18,19}$

\section{Elderly}

The elderly patient is generally treated on a case to case basis. Interventions and drugs carry a higher complication rate due to comorbidities and procedural risk. Physically

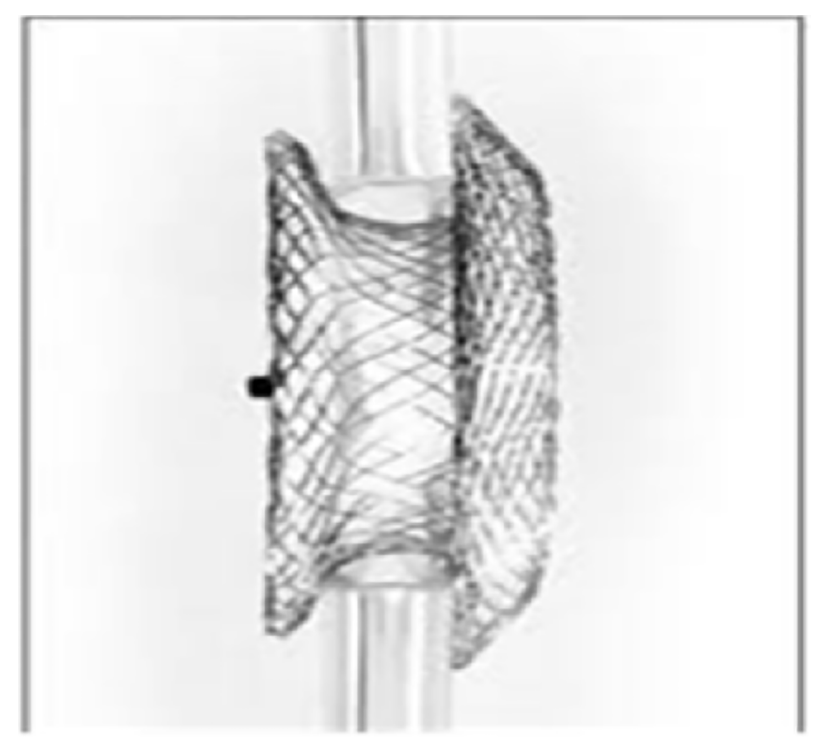

Figure 7 Figulla Occlutech septal occluder (Occlutech GmbH, Jena, Germany). 
active and cognitively intact elderly are offered ASD closure. Device choice is based on anatomical structure. A quality of life benefit is usually obtained from a geriatrician before embarking on such a procedure.

\section{Conclusion}

The range of ASD closure devices has facilitated percutaneous closure for simple and complex septal defects. The safety and feasibility studies show high levels of deployment success and recognizable features that predispose to complications. The wide range of sizes meets the needs of most defects with only a small number of contraindications. The introduction of biodegradable technology and nickel free products may minimize long-term sequelae. Delivery mechanisms that minimize air embolism and allow for flexibility is an added advantage in avoiding complications. The continued development of ASD device technology as well as long-term success with current devices will ensure that percutaneous transcatheter ASD closure remains a preferred procedure.

\section{Acknowledgment}

The author thanks Professor Jonathan Tobis (UCLA Medical Center) for input on preparing this review.

\section{Disclosure}

The author has no conflicts of interest to disclose.

\section{References}

1. Warnes CA, Williams RG, Bashore TM, et al. ACC/AHA 2008 Guidelines for the management of adults with Congenital Heart Disease: Executive Summary: a report of the American College of Cardiology/American Heart Association task force on practice guidelines. Circulation. 2008;118(23):2395-2345.

2. US Food and Drug Administration [homepage on the Internet]. Medical Device Safety Communications. Available from: http://www.fda.gov/ MedicalDevices/Safety/AlertsandNotices. Accessed March 30, 2015.

3. Therien J, Webb GD. Congenital heart diseases in adults. In: Braunwald E, Zipes DP, Libby P, editors. Heart Disease: A Textbook of Cardiovascular Medicine. 6th ed. Philadelphia, USA: WB Saunders; 2001: 1592-621.

4. Prokselj K, Kozelj M, Zadnik V, PodnarT. Echocardiographic characteristics of secundum-type atrial septal defects in adult patients: implications for percutaneous closure using Amplatzer septal occluders. J Am Soc Echocardiogr. 2004;17(11):1167-1172.
5. Butera G, Romagnoli E, Carminati M, et al. Treatment of isolated secundum atrial septal defects: impact of age and defect morphology in 1,013 consecutive patients. Am Heart J. 2008;156(4):706-712.

6. Pavlovic M, Buellesfeld L, Meier B. Tools and techniques: PFO/ASD closure. EuroIntervention. 2014;7(3):66-69.

7. El-Said H, Hegde S, Foerster S, et al. Device therapy for atrial septal defects in a multi-center cohort: acute outcomes and adverse events. Catheter Cardiovasc Interv. 2015;85(2):227-233.

8. Boutin C, Musewe NN, Smallhorn JF, Dyck JD, Kobayashi T, Benson LN. Echocardiographic follow-up of atrial septal defect after catheter closure by double-umbrella device. Circulation. 1993;88(2): 621-627.

9. Behjati M, Rafiei, M, Soltani, MH, Emami, M, Dehghani M. Transcatheter closure of atrial septal defect with amplatzer septal occluder in adults: immediate, short, and intermediate-term results. J Tehran Heart Cent. 2011;6(2):79-84.

10. Crawford GB, Brindis RG, Krucoff MW, Mansalis BP, Carroll JD. Percutaneous atrial septal occluder devices and cardiac erosion: a review of the literature. Catheter Cardiovasc Interv. 2012;80(2):157-167.

11. Jones TK, Latson LA, Zahn E, et al. Results of the US multicenter pivotal study of the HELEX septal occluder for percutaneous closure of secundum atrial septal defects. J Am Coll Cardiol. 2007;49(22): $2215-2221$.

12. Freixa $X$, Ibrahim $R$, Chan J, et al. Initial clinical experience with the GORE septal occluder for the treatment of atrial septal defects and patent foramen ovale. EurIntervention. 2013;9(5):629-635.

13. Kaya M, Akpek M, Celebi A, et al. Initial clinical experience with the GORE septal occluder for the treatment of atrial septal defects and patent foramen ovale. EuroIntervention. 2014;10:626-631.

14. Wertman B, Azarbal B, Riedl M, Tobis J. Adverse events associated with nickel allergy in patients undergoing percutaneous atrial septal defect or patent foramen ovale closure. J Am Coll Cardiol. 2006;47(6): $1226-1227$

15. Nugent AW, Britt A, Gauvreau K, Piercey GE, Lock JE, Jenkins KJ. Device closure rates of simple atrial septal defects optimized by the STARFlex Device. J Am Coll Cardiol. 2006;48(3):538-544.

16. Morgan G, Lee KJ, Chaturvedi R, Benson L. A biodegradable device (BioSTAR) for atrial septal defect closure in children. Catheter Cardiovasc Interv. 2010;76(2):241-245.

17. Baspinar O, Kervancioglu M, Kilinc M, Irmet A. Bioabsorbable atrial septal occluder for percutaneous closure of atrial septal defect in children. Tex Heart Inst J. 2012;39(2):184-189.

18. Godart F, Houeijeh A, Recher M, et al. Transcatheter closure of atrial septal defect with the figulla ASD occluder: a comparative study with the Amplatzer Septal Occluder. Arch Cardiovasc Dis. 2015;108(1): 57-63.

19. Haas N, Happel C, Soetemann D, et al. Optimal septum alignment of the Figulla ${ }^{\circledR}$ Flex occluder to the atrial septum in patients with secundum atrial septal defects. EuroIntervention. Epub December 16, 2014.
Medical Devices: Evidence and Research

\section{Publish your work in this journal}

Medical Devices: Evidence and Research is an international, peerreviewed, open access journal that focuses on the evidence, technology, research, and expert opinion supporting the use and application of medical devices in the diagnosis, treatment and management of clinical conditions and physiological processes. The identification of novel

\section{Dovepress}

devices and optimal use of existing devices which will lead to improved clinical outcomes and more effective patient management and safety is a key feature. The manuscript management system is completely online and includes a quick and fair peer-review system. Visit http://www. dovepress.com/testimonials.php to read real quotes from authors. 